\title{
Heterospecific competition and attraction in grassland bird communities differ with habitat quality
}

\author{
S. L. McGuire ${ }^{1}$ and J. J. Nocera ${ }^{2}$ \\ ${ }^{1}$ Corresponding author. Environmental and Life Sciences Graduate Program, Trent University, 1600 West Bank Drive, \\ Peterborough, Ontario, Canada, K9J 7B8. Email: slmcguire@gmail.com. Phone: 1-705-931-4221 \\ 2 Ontario Ministry of Natural Resources \& Forestry, DNA Building, Trent University, 2140 East Bank Drive, \\ Peterborough, Ontario, Canada, K9J 7B8. Email: joe.nocera@ontario.ca Phone: 1-705-755-5220
}

Keywords: BACI, Community ecology, Conspecific attraction, Grassland birds.

\begin{abstract}
The behavioral basis for habitat selection has been intensively studied, but comparatively little attention has been paid to how the resultant species assemblages are formed or affected. Further, how habitat quality interacts with behavior during habitat selection needs greater exploration. We sought to identify some of the behavioral interactions influencing the development of bird assemblages in agricultural habitats, which we consider a structurally simple model system. We performed point counts in non-cultivated meadows, intensive agriculture, and non-intensive agriculture areas in the 2011 and 2012 breeding seasons in which we particularly focussed on Bobolink (Dolichonyx oryzivorus), Eastern Meadowlark (Sturnella magna), Field Sparrow (Spizella pusilla), Grasshopper Sparrow (Ammodramus savannarum), Savannah Sparrow (Passerculus sandwichensis), and Vesper Sparrow (Pooecetus gramineus). Using presence-absence matrices and EcoSim software on 2011 census data, we determined where competition was likely to occur, and which species were competing. In 2012, we experimentally tested these relationships by introducing artificial competitors onto sites. We implemented a before-after control-impact study by comparing presence-absence data from 2011 to 2012 and using multinomial logistic regression. We found grassland bird assemblages are structured by interspecific competition or attraction. The experimental introduction of Grasshopper Sparrows resulted in several presence/absence changes, which differed based on habitat quality, by conspecifics and four heterospecifics (especially Bobolinks). We speculate that the response to competitors is actually determined by the relative quality of each habitat type for each species.
\end{abstract}

Nomenclature: American Ornithologists' Union Checklist of North and Middle American Birds.

Abbreviations: BACI - before-after control-impact, CONT - control, C-score - checkerboard score, DF - degrees of freedom, FISP - Field Sparrow decoy and playback, GRSP - Grasshopper Sparrow decoy and playback, IAG - intensive agriculture, $\mathrm{NAG}$ - non-intensive agriculture, $\mathrm{NCM}$ - non-cultivated meadow, obs = observed matrices, $\mathrm{sim}=$ simulated matrices.

\section{Introduction}

Some of the most important factors influencing avian habitat choice are the selection of foraging substrates, food resources, and avoidance of competition (Terborgh 1985). The existence of competition and its role in structuring animal communities has a long history of study (e.g., Elton 1946), but can be contentious (Connor and Simberloff 1979, Strong et al. 1979, Roughgarden 1983). However, since competition occurs in a variety of communities with many different mechanisms (Roughgarden 1983), many nuances of interspecific interactions remain to be explored. Understanding the relationship between interspecific competition and attraction is especially important in communities that support multiple vulnerable species, since conservation efforts for one species may have unintended effects on others and disrupt the preexisting community (Fletcher 2007, Betts et al. 2010).

In this study, we define conspecific attraction as the increased probability that an individual will settle in a site where individuals of the same species are already present. Heterospecific attraction is the increased probability that an individual will settle in a site where there are individuals of different species. While conspecific attraction in bird communities has been well-studied (Ray et al. 1991, Ward and Schlossberg 2004, Nocera et al. 2006, Betts et al. 2008), more research is needed on the effects of heterospecific attraction from a community ecology perspective (Nocera and Betts 2010). Conspecific attraction has benefits such as more efficient detection of predators, increased likelihood of finding a mate, more opportunities for extra-pair fertilizations, and settlement in habitats of higher quality (Ahlering and Faaborg 2006, Ahlering et al. 2006, Fletcher 2006). Some of these benefits can also be conferred between or among species, especially if one species is resident and the other is a migrant who must quickly gain information about habitat quality upon arrival (Mönkkönen et al. 1990, Fletcher 2007, Nocera and Betts 2010). Migrant Pied Flycatchers (Ficedula hypoleuca) are attracted to resident Titmice (Parus spp.), and in 
their presence have earlier breeding, larger brood and nestling size, better foraging, and decreased predation than in their absence (Forsman et al. 2002). These advantages may also be true between migrant species, if one arrives and settles in habitats earlier than the other (Seppänen et al. 2007). However, these kinds of social interactions can be complicated, as there is often a trade-off between using the information collected from others and competing with the informer for resources (Fletcher 2007, Seppänen et al. 2007). Interspecific competition occurs when ecological niches of two species overlap closely (Miller and Hackett 2011), and this competition may result in exclusion if resources are insufficient to sustain both species (Hardin 1960, Miller and Hackett 2011, but see Sinclair 1991). Population density mediates the response of Least Flycatchers (Empidonax minimus) to the presence of American Redstarts (Setophaga ruticilla); attraction of flycatchers to redstarts is strongest at moderate Redstart densities, whereas at high densities the cost of competing is greater than the benefits of attraction (Fletcher 2007). When conspecific decoys and song playbacks are used to attract BlackThroated Blue Warblers (Dendroica caerulescens) to settle at experimental sites, other species avoid those sites, which suggests they are experiencing interspecific competition from the warblers or are pre-emptively excluded (Betts et al. 2010).

Determining the role of community assembly in habitat selection is easiest in structurally simple systems because the effects of experimental manipulation of the environment are easier to evaluate (Styring et al. 2011). The study of agroecosystems can be useful for such purposes, as they typically have one main crop type which supports an assemblage that is less species-rich than the natural grasslands; they are usually simple in structure, and easy to define. Of particular conservation interest in North American agro-ecosystems is the grassland bird community, because much of the land converted to agriculture was originally grassland, which resulted in grassland bird populations being displaced and/or reduced (Askins 1993, 2000). Many North American grassland bird species are listed as at-risk (e.g., in Ontario, Canada) or are known to be in population decline (see species-specific accounts in: Martin and Gavin 1995, Vickery 1996, Jones and Cornely 2002, Carey et al. 2008, COSSARO 2010, 2011, Jaster et al 2012).

To study the effect of heterospecific attraction and exclusion on community assembly, we studied three kinds of cultivated habitats in southern Ontario, Canada with the aims of determining: (a) the structure of grassland bird communities in southern Ontario agro-ecosystems and (b) whether simulating the presence of other species would induce competition or attraction and alter such structure. We achieved our first objective by analyzing species presence-absence data for patterns of co-occurrence. We achieved our second objective by implementing a before-after control-impact (BACI) study to experimentally evaluate interspecific competition. Recognizing the importance of habitat quality, we predicted that assemblage of bird species on agricultural fields would be determined by habitat type and interspecific interactions. In addition to the heterospecific effects monitored in our BACI study, we also predicted that the experimental placement of simulated competitors/facilitators on sites would result in varying degrees of conspecific attraction across all habitat types. Our results confirmed these predictions; grassland bird assemblages in certain habitat types are structured by interspecific competition or attraction, dependent on the species-specific habitat quality.

\section{Methods}

\section{Data collection}

To census the grassland bird communities that were in place before our experiments, we performed five-minute point counts at 68 sites across Northumberland County, Ontario from 31 May to 30 July 2011. In 2012, all sites were again censused using the same methods during and after experimental manipulation (see Experimental treatments). We censused birds across three different habitat types: intensively cultivated agricultural areas (IAG) that included fields of grain, maize and soybean; hay meadows and pastures were our non-intensively cultivated study areas (NAG), and the third habitat type was shrubby successional fields that were not cultivated at all (non-cultivated meadows, NCM). Observers performed five-minute point counts from the roadside, between dawn $(05 \mathrm{~h} 30-06 \mathrm{~h} 00)$ and $10 \mathrm{~h} 00$ (Eastern Daylight Time). Counts were not conducted if it was raining, foggy, or the wind was $>20 \mathrm{~km} /$ hour. We counted each site approximately every 5-7 days and recorded all birds identified by sight or sound. Our focal grassland species were chosen because they were species of conservation concern in Ontario and/or the most abundant in any of our three agricultural habitat types. These species were Bobolink (Dolichonyx oryzivorous), Eastern Meadowlark (Sturnella magna), Field Sparrow (Spizella pusilla), Grasshopper Sparrow (Ammodramus savarannum), Savannah Sparrow (Passerculus sandwichensis), and Vesper Sparrow (Pooecetes gramineus).

\section{Presence-absence analysis}

We hypothesized that competition or attraction between species contributed to grassland bird community composition in agro-ecosystems. To investigate this, we first generated presence-absence matrices by habitat type (NAG, IAG, and NCM) from the 2011 point count data. We then used methods described in Gotelli (2000) to analyse these matrices for patterns of species co-occurrence. We used the "checkerboard score" (C-score, Gotelli 2000) index, to compare presenceabsence matrices to what would be expected under a null hypothesis. A checkerboard distribution occurs when Species A is found in Site 1 but not Site 2, and Species B is found in Site 2 but not Site 1; the sites must be adjacent to each other in the matrix. However, the C-score allows segregation to be measured from non-adjacent sites. Further, it is not prone to Type II error and is insensitive to noisy data (Gotelli 2000). We chose the algorithm SIM9 (Gotelli 2000), which keeps the row sums (total sites per species) and column sums (total species per site) fixed to fill the null matrices. SIM9 is not prone to Type I error, and Gotelli (2000) recommends using the C-score and SIM9 in combination. We used EcoSim soft- 
ware (Entsminger 2012) to fill 5000 null presence-absence matrices based on the SIM9 algorithm and compare their $\mathrm{C}$-scores to the $\mathrm{C}$-score of our original matrices (one for each habitat type). If the $\mathrm{C}$-score of our matrix was significantly higher than the $\mathrm{C}$-scores of the null matrices, this suggested competition in this habitat type. If the $\mathrm{C}$-score from our matrix was significantly lower than that of the null matrices, this suggested facilitation in a habitat type. Facilitation occurs when there are positive interactions between two species (e.g., attraction), which harms neither and benefits at least one of them (Bruno et al. 2003). In our system, we speculated that the presence of one bird species may serve as a signal to another that the habitat is of good quality (i.e., heterospecific attraction; Seppänen et al. 2007). These indices allowed us to determine in which habitat types competition or facilitation between species was likely. EcoSim also produced a C-score for each species pair, which allowed us to evaluate which species pairs showed the strongest apparent competition or facilitation.

\section{Experimental treatments}

Preliminary analysis of our 2011 census data showed that the presence-absence of Field and Grasshopper Sparrows was associated with the presence-absence of the four remaining focal species. From 29 April - 9 June 2012, we placed a decoy and broadcast song playbacks on a subset of sites on which we conducted point counts in 2011. Playbacks were designed to mimic natural singing rates of the two species; every 25 seconds for Grasshopper Sparrow and every 10-15 seconds for Field Sparrow (Proppe and Ritchison 2008, Heckenlively 1976, respectively). The decoys and playbacks were deployed once weekly for $\geq 30$ minutes, which required a batterypowered portable CD player (Insignia NS-P4112, $\geq 70 \mathrm{~dB}$ ), speakers (Logitech LS11), and a realistic hand-painted clay decoy on top of a thin bamboo pole. Each site received one of three treatments repeatedly over the six weeks: 1) a decoy and playback of Grasshopper Sparrow (hereafter "GRSP"), 2) a decoy and playback of Field Sparrow (hereafter "FISP"), or 3) a control treatment (hereafter "CONT") where no sound was broadcast and no decoy was deployed, but the speakers, battery pack, and bamboo pole were deployed to control for the simple presence of the objects. The GRSP and FISP treatments were each deployed at non-intensive agriculture sites ( $n=3$ per treatment type), intensive agricultural sites $(n=3$ per treatment type) and non-cultivated meadow sites $(n=3$ per treatment type). Control treatments were deployed at 2 sites per habitat type.

\section{Behavioral observations}

Once we placed the treatment on the field, we continuously observed at each site for 10 minutes after the first bird approached to within 15 metres of the decoy. We continued the observations successively with each new bird to respond for $\leq 30 \mathrm{~min}$ after the first response of the first bird. If no birds responded, we still observed for $\geq 30 \mathrm{~min}$ after the placement of a decoy and playback so that all sites had $\geq 30 \mathrm{~min}$ of playback and decoy exposure per week. Observers stood 10
Table 1. Possible activities of birds recorded during observations of treatment deployment on experimental sites.

\begin{tabular}{|c|c|}
\hline Behavior & Description \\
\hline Song & $\begin{array}{l}\text { Primary or secondary song types } \\
\text { given outside of a flight display }\end{array}$ \\
\hline Call & $\begin{array}{l}\text { Other vocalizations which are } \\
\text { not primary or secondary song }\end{array}$ \\
\hline Flight & $\begin{array}{l}\text { Directional flight which is not } \\
\text { part of a flight display }\end{array}$ \\
\hline Agonistic flight display & $\begin{array}{l}\text { Species-specific but generally } \\
\text { includes song-flights, flutter- } \\
\text { flights, swooping/diving }\end{array}$ \\
\hline Agonistic stationary display & $\begin{array}{l}\text { Species-specific but generally } \\
\text { includes song-spread and vari- } \\
\text { ous aggressive behaviors from } \\
\text { ground or perch }\end{array}$ \\
\hline
\end{tabular}

$m$ outside the observation area and dictated all bird responses (Table 1) that occurred within $15 \mathrm{~m}$ of the set-up (i.e., a $30 \mathrm{~m}$ diameter circle around the experimental set-up) into a handheld recording device for later transcription. For each bird within the observation area, we also noted the distance to the experimental set-up.

\section{Before-after control-impact analysis}

To test whether deployment of GRSP or FISP treatments had an effect on grassland bird communities, we used a before-after control-impact design in which we compared the presence-absence of birds in 2011 ("before") to the presenceabsence of birds on the same sites in 2012, after we simulated the presence of species which were putative competitors (see Experimental treatments). This allowed us to treat the point counts in 2011 as "controls" to compare to the point counts in 2012 to determine the "impact" of the competitive/facilitative species on the settlement choices of other bird species.

To determine the change in occupancy for each site, we subtracted a value for the presence (1) or absence (0) determined per site per species in 2012 from the value in the same sites in 2011 to quantify the change for each species where: a score of 0 (stability) meant there was no change from 2011 to 2012, so either the site had the species and retained it, or did not have the species either year; a score of -1 (loss) meant that the site had the species in 2011 but lost it in 2012; and a score of +1 (gain) meant that the site did not have the species in 2011 but gained it in 2012. All non-manipulated sites, including sites on which the control set-up was placed for behavioral observations, were included as part of the CONT model for the BACI analysis. We examined the scores by treatment to determine the effect of FISP, GRSP, and CONT. To avoid singularities in the data, we summed the changes across all sites for each species, separately for each treatment (CONT, FISP, and GRSP), and removed any species whose absolute net change summed across all sites was $\leq 1$ (Table 2 ). Although we had six focal species for this study, we also included all detected bird species whose absolute net change summed across all sites was $\geq 1$ in the model so that any ef- 
Table 2. List of species included as main effects after removing singularities in each treatment model.

\begin{tabular}{cl}
\hline Treatment & \multicolumn{1}{c}{ Species and Code } \\
\hline & American Goldfinch (AMGO); American \\
& Robin (AMRO); Barn Swallow (BARS); \\
& Black-capped Chickadee (BCCH); Brown- \\
headed Cowbird (BHCO); Blue Jay (BLJA); & Bobolink (BOBO); Brown Thrasher \\
& (BRTH); Cedar Waxwing (CEDW); \\
& Chestnut-sided Warbler (CSWA); Eastern \\
& Bluebird (EABL); Eastern Kingbird (EAKI); \\
& Eastern Wood-Pewee (EAWP); Field \\
& Sparrow (FISP); Great Crested Flycatcher \\
& (GCFL); Horned Lark (HOLA); House Wren \\
& (HOWR); Indigo Bunting (INBU); Killdeer \\
& (KILL); Least Flycatcher (LEFL); Mourning \\
& Dove (MODO); Northern Cardinal (NOCA); \\
& Rose-Breasted Grosbeak (RBGR); Red- \\
& Winged Blackbird (RWBL); Savannah \\
& Sparrow (SAVS); Song Sparrow (SOSP); \\
& Vesper Sparrow (VESP); Willow Flycatcher \\
& (WIFL); Yellow-Shafted (Northern) Flicker \\
& (YSFL); Yellow Warbler (YWAR) \\
& \\
& Barn Swallow (BARS); Brown Thrasher \\
& (BRTH); Cedar Waxwing (CEDW); \\
& Chipping Sparrow (CHSP); Common \\
Yellowthroat (COYE); Eastern Kingbird \\
(EAKI); House Wren (HOWR); Mourning \\
Dove (MODO); Northern Cardinal (NOCA); \\
Savannah Sparrow (SAVS) \\
\\
Alder Flycatcher (ALFL); American \\
Goldfinch (AMGO); Brown-headed \\
Cowbird (BHCO); Bobolink (BOBO); \\
Cedar Waxwing (CEDW); Eastern Phoebe \\
(EAPH); European Starling (EUST); Gray \\
Catbird (GRCA); Grasshopper Sparrow \\
(GRSP); Killdeer (KILL); Mourning Dove \\
(MODO); Willow Flycatcher (WIFL); \\
Yellow Warbler (YWAR) \\
\hline
\end{tabular}

fects of the experimental treatments on other species' presence-absence were not overlooked.

Although we coded the species changes between years as numbers, they are not ordinal but instead represent loss, gain, or stability. We first used linear mixed effects models to determine the effect of our independent variables of species (Table 2) and habitat (NAG, IAG, NCM) on our dependent variable of species change (loss, stability, or gain), specifying site as a random factor. We used the 'nlme' package (Pinheiro et al. 2013) in R statistical software (R Development Core Team 2013) to run a separate model for each treatment (FISP, GRSP, and CONT). Following this, we used multinomial logistic regression (Starkweather and Moske 2011) to further explore the effect of our treatments on specific species in specific habitats. Both dependent and independent variables were categorical; our main effects in the model were habitat (NAG, IAG, NCM) and species (Table 2) while our dependent variable was change in occupancy (loss, stability, or gain). We used the 'multinom' function in the 'nnet' package (Venables and Ripley 2002) in R statistical software to run a separate model for each treatment (FISP, GRSP, and CONT). Multinomial logistic regression runs multiple logistic regressions to make all possible comparisons to a specified reference level of the dependent variable. For these models, we specified loss as the reference level. This was an arbitrary choice and had no real consequence for the results of the model. The output provided coefficients for two logistic regressions, one for loss vs. stability and one for loss vs. gain. This means that we modeled the probability of losing a species versus no change, and the probability of losing a species versus gaining a species, based on the factors of habitat and species present. We exponentiated the coefficients of the models to obtain odds ratios, then divided the odds ratio for IAG by the odds ratio for NAG to get the magnitude of the difference in odds ratios between those habitat types. We contrasted the odd ratios in this way for each species within each model (FISP, GRSP, CONT) for both comparisons (loss vs. stability and loss vs. gain). This allowed us to interpret the effect of habitat type on the results of the BACI study. For example, if the difference in odds ratios for loss vs. gain for Bobolink in the FISP model was close to 1, this showed that the odds of gaining Bobolink were relatively equal in IAG and NAG for sites treated with FISP. However, if the difference in odds ratios for loss vs. gain for Bobolink in the GRSP model was large and negative, this showed that the odds of gaining Bobolink in IAG was much greater than the odds of gaining Bobolink in NAG for sites treated with GRSP. Finally, if the difference in odds ratios for loss vs. gain for Grasshopper Sparrow in the CONT model was large and positive, this would mean that the odds of gaining Grasshopper Sparrow in NAG was much greater than the odds of gaining Grasshopper Sparrow in IAG for fields treated with CONT. By examining the magnitude of the differences in odds ratios in the CONT model, we observed that, with the exception of Eastern Wood-Pewee (Contopus virens) in the loss vs. gain contrast $\left(1.54 \times 10^{-17}\right)$, the magnitude did not exceed an absolute value of $7.49 \times 10^{9}$. Therefore, when evaluating the FISP and the GRSP model, magnitudes with an absolute value $>7.49 \times 10^{9}$ were considered meaningful. Eastern Wood-Pewee does not appear in either of these two models, and so was not influenced by a large outlying value from the CONT model. This approach allowed us to contrast the FISP and the GRSP treatments with the CONT sites between 2011 and 2012, and determine whether FISP or GRSP sites showed disproportionately more loss, stability, or gain in relation to CONT sites.

\section{Results}

C-scores varied by habitat in 2011 (Table 3). No habitat had an observed index less than or equal to the mean simulated index. NAG and IAG had observed indices significantly greater than their mean simulated indices ( $\mathrm{p}$ [observed $>$ simulated $]=0.017$ and 0.067 , respectively)

Five species pairs showed high C-scores across all habitat types (Table 4), which were all derived from just six species. The range of all C-scores was 0-75; a full table of the C-scores can be found in Electronic Appendix 1. A high C-score means that while both species were found in that habitat type, they rarely occurred on the same site; e.g., while Grasshopper Sparrow and Red-winged Blackbird (Agelaius phoeniceus) 
Table 3. Checkerboard scores and significance tests for each habitat type. $\alpha=0.1$ for all.

\begin{tabular}{lcccc}
\hline \multicolumn{1}{c}{ Habitat } & Observed C-score & $\begin{array}{c}\text { Mean Simulated } \\
\text { C-score }\end{array}$ & $\begin{array}{c}\text { Variance of Simulated } \\
\text { C-score }\end{array}$ & P(obs $>$ sim $)$ \\
\hline Non-cultivated Meadow & 3.54204 & 3.50100 & 0.00166 & 0.158 \\
Intensive Agriculture & 13.32254 & 13.12968 & 0.01539 & $0.067^{*}$ \\
Non-intensive Agriculture & 10.51341 & 10.22883 & 0.01222 & $0.017^{*}$ \\
\hline
\end{tabular}

Table 4. Checker-board scores and habitat type for the five top-scoring species pairs.

\begin{tabular}{cccc}
\hline Species 1 & Species 2 & Habitat & C-score \\
\hline Field Sparrow & Bobolink & Non-intensive agriculture & 42 \\
Field Sparrow & Red-winged Blackbird & Non-intensive agriculture & 52 \\
Grasshopper Sparrow & Red-winged Blackbird & Non-intensive agriculture & 75 \\
Grasshopper Sparrow & Savannah Sparrow & Intensive agriculture & 50 \\
Grasshopper Sparrow & Vesper Sparrow & Intensive agriculture & 32 \\
\hline
\end{tabular}

Table 5. Results of the linear mixed effects model on change in species occupancy (A, B, or C, see Methods) for each treatment. $\alpha=$ 0.1 for all.

\begin{tabular}{lccccr}
\hline Model & Coefficient & Numerator DF & Denominator DF & F-value & P-value \\
\hline \multirow{3}{*}{ CONT } & Species & 29 & 1392 & 2.691 & $<0.0001^{*}$ \\
& Habitat & 2 & 48 & 3.412 & $0.0411^{*}$ \\
& Species:Habitat & 58 & 1392 & 1.239 & 0.110 \\
\multirow{3}{*}{ FISP } & Species & 9 & 45 & 2.723 & $0.0126^{*}$ \\
& Habitat & 2 & 4 & 0.458 & 0.6568 \\
& Species:Habitat & 18 & 45 & 1.162 & 0.3307 \\
\multirow{3}{*}{ GRSP } & Species & 12 & 72 & 3.093 & $0.0014^{*}$ \\
& Habitat & 2 & 6 & 3.370 & 0.104 \\
& Species:Habitat & 24 & 72 & 1.204 & 0.269 \\
\hline
\end{tabular}

were both found in NAG fields, a C-score of 75 means they were not often found on the same field.

We did not observe any direct interspecific agonistic behaviors. However, conspecifics (where present), especially Grasshopper Sparrows, responded readily to the decoys and playback. Observed behaviours included flying and singing within $5 \mathrm{~m}$ of the decoy, diving at the decoy, and striking at decoy with feet and wings.

The presence or absence of certain bird species changed between years based on whether the presence of FISP or GRSP was simulated on the site (see Electronic Appendix 2). The CONT treatment had an extremely large number of rows due to having more species $(n=30)$ and sites $(n=50)$ than the other two treatments, but there were no significant changes between years.

The linear mixed effects model revealed responses for each treatment (Table 5). In CONT experiments, coefficients for both species and habitat were significant $\left(\mathrm{F}_{29,2}=2.69\right.$, $\left.\mathrm{p}<0.0001 ; \mathrm{F}_{2,48}=3.41, \mathrm{p}=0.0411\right)$. The species coefficient for both FISP and GRSP models was significant $\left(\mathrm{F}_{9.45}=2.72\right.$, $\left.\mathrm{p}=0.013 ; \mathrm{F}_{12,72}=3.09, \mathrm{p}=0.0014\right)$.

The magnitude of the differences varied between the odds ratios for both contrasts (loss vs. stability and loss vs. gain) in IAG compared to NAG for each species in each multi- nomial logistic regression model (c). The magnitude of the difference in loss vs. stability odds ratios between IAG and NAG for Brown Thrasher (Toxostoma rufum) in the FISP model was meaningful $\left(8.77 \times 10^{-12}\right)$ as was the magnitude of the difference in loss vs. gain odds ratios for House Wren (Troglodytes aedon) $\left(2.30 \times 10^{10}\right)$. The magnitude of the difference in loss vs. stability odds ratios between IAG and NAG in the GRSP model was meaningful for Brown-headed Cowbird (Molothrus ater), European Starling (Sturnus vulgaris), Grasshopper Sparrow, and Killdeer (Charadrius vociferus $)\left(3.70 \times 10^{-20}, 4.56 \times 10^{21}, 3.08 \times 10^{-18}\right.$, and $1.17 \times$ $10^{15}$, respectively). Further, the magnitude of the difference in loss vs. gain odds ratios was meaningful in the GRSP model for Bobolink, European Starling, and Grasshopper Sparrow $\left(2.17 \times 10^{-11}, 1.12 \times 10^{10}\right.$, and $1.57 \times 10^{-29}$, respectively $)$. The $\log$ of these differences in magnitude, as well as their significance, varied in the FISP and GRSP models (Figures 1-3).

\section{Discussion}

\section{Checkerboard scores}

We found that bird assemblages in both NAG and IAG habitats were structured by interspecific competition. Their $\mathrm{C}$-scores were significantly higher than those of the null 

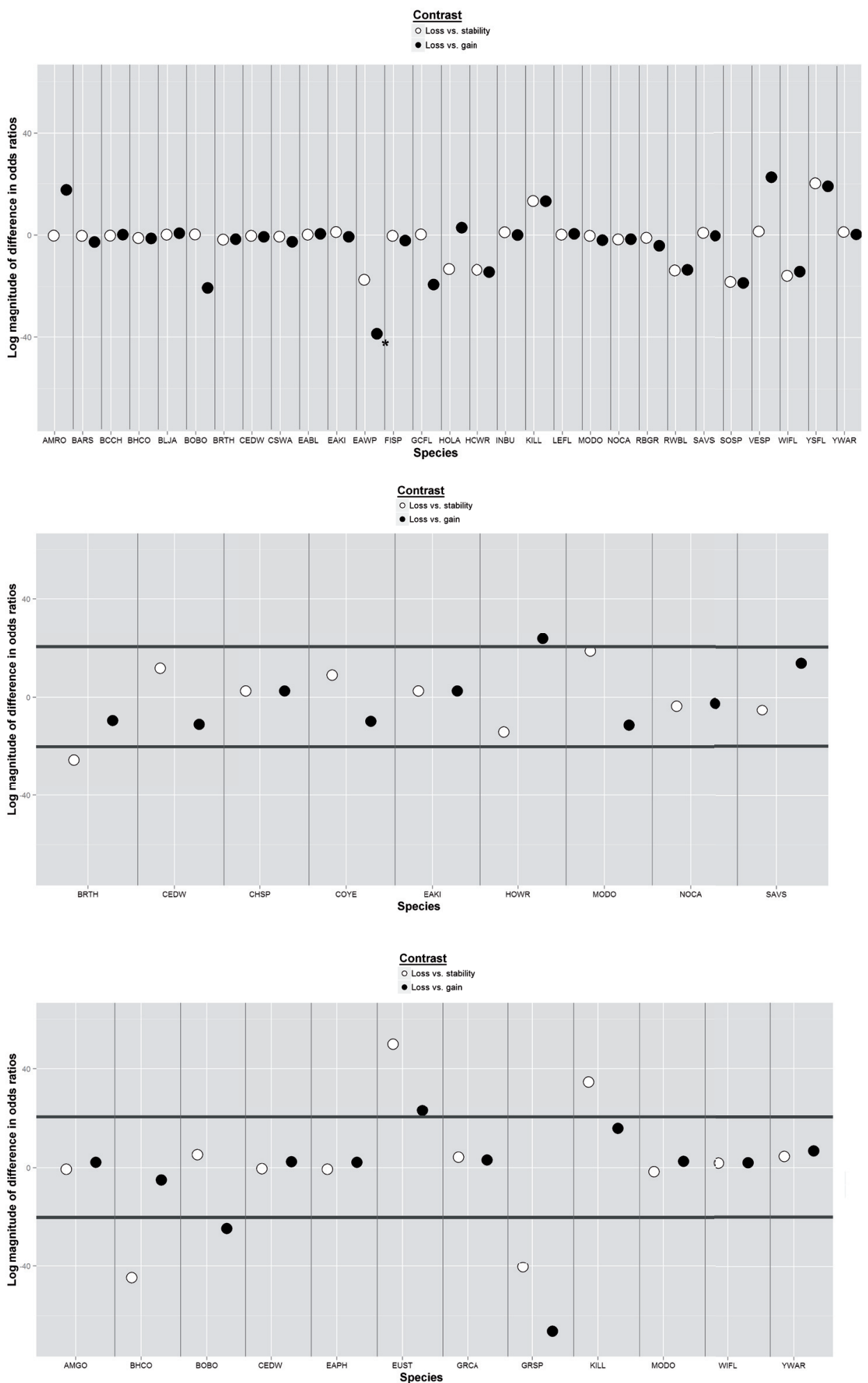

Figure 1. Categorical scatterplot showing the $\log$ of the magnitudes of the differences in odds ratios for each species in the control model. The star marks an abnormally large value. See Table 3 for definitions of species codes.

Figure 2. Categorical scatterplot showing the $\log$ of the magnitudes of the differences in odds ratios for each species in the Field Sparrow model. The horizontal lines show the extent of the control model values; points above the top line and below the bottom line are considered important. See Table 3 for definitions of species codes.

Figure 3. Categorical scatterplot showing the $\log$ of the magnitudes of the differences in odds ratios for each species in the Grasshopper Sparrow model. The horizontal lines show the extent of the control model values; points above the top line and below the bottom line are considered important. See Table 3 for definitions of species codes. matrices, and the odds-ratio comparisons showed varied responses of bird species to the introduction of competitors on these habitat types. However, these interactions were not always in the expected direction(s).

Based on pre-experiment community data, we expected that the introduction of FISP treatments would affect the occurrence of Red-winged Blackbird and Bobolink, while
GRSP treatments would affect the occurrence of Red-winged Blackbird, Savannah Sparrow, and Vesper Sparrow. However, only the presence/absence of Bobolinks appears to have been affected by the treatments, and by GRSP rather than FISP. Further, except for normal flight and song behaviors that resulted in an inadvertent approach within $15 \mathrm{~m}$ of the decoy, no direct interspecific competitive interactions were observed during the study. This may be because direct interspecific al- 
tercations are generally rarer than those between conspecifics as interspecifics compete for food and space, not territories and mates. Second, our treatments may not have been deployed on fields for long enough to elicit the expected direct response from interspecifics. The experimental set-up also may have had limitations in (a) that playback was clearly audible at $30 \mathrm{~m}$ from the decoy (i.e., was $>70 \mathrm{db}$ ), but it may not have carried far enough to reach all birds on the site, and/ or (b) although we made efforts to be unobtrusive and sit far enough from the decoy, the presence of an observer at the site during treatment may have influenced the reaction of the birds. However, these factors are unlikely to have influenced any indirect effects of the introduction of competitors, i.e., the change in site occupancy used in the linear mixed effects model and the multinomial logistic regression.

\section{Odds ratio differences between habitats}

Grassland bird assemblages in both IAG and NAG habitats appeared to be structured by interspecific competition or attraction, both of which depend on species-specific habitat quality. Previous work on habitat use by grassland birds in agro-ecosystems has shown that NAG sites appear to be of higher quality than IAG sites (Boren et al. 1997, Conover et al. 2011, McGuire 2014). The different responses of a species to an introduced potential competitor can be explained by their habitat use; when in habitat of lesser quality, birds are more likely to be deterred by a competitor (e.g., Grasshopper Sparrow in IAG). Further, some species show attraction to introduced heterospecifics when in high-quality habitat (e.g., Bobolink in NAG).

In our multinomial logistic regression "loss" is the reference level for both contrasts (loss vs. stability and loss vs. gain) and corresponds to a score of 0 in a traditional logistic regression. Given this, our results showed that the introduction of a FISP model was important in determining the presence of Brown Thrasher and House Wren. The magnitude of the difference in loss vs. stability odds ratios for Brown Thrasher (Electronic Appendix 3) means that while the odds of no change were greater than the odds of losing Brown Thrasher for both, they were substantially larger in NAG than IAG. Thus, the introduction of the FISP treatment had no effect in either IAG or NAG sites, but any effect was nonetheless lower in NAG than IAG. Whereas the loss vs. gain odds ratio for House Wren was larger in IAG than NAG (Electronic Appendix 3), which means the odds of gaining House Wren were substantially greater in IAG than NAG. The magnitude of the differences indicate that in IAG, the probability of gaining House Wren was greater than the probability of losing it, but in NAG, the opposite was more likely. This shows that the treatment of sites with FISP resulted in the attraction of House Wren to IAG sites, but their deterrence from NAG sites. However, Brown Thrasher and House Wren are not typical grassland species (Johnson 1998, Cavitt and Haas 2000) nor do they have any known impact on grassland species. Since the FISP treatment had a significant effect only on those two species, it is clear that FISP treatment had little effect on the grassland bird community (see Checkerboard scores above).

Conversely, we found that in the GRSP model, the magnitude of the difference in loss vs. stability odds ratios was meaningful for Grasshopper Sparrow, Brown-headed Cowbird, European Starling, and Killdeer. We also found that the magnitude of the difference in loss vs. gain odds ratios in the GRSP model was meaningful for Grasshopper Sparrow, Bobolink, and European Starling. These results support our prediction that competition is mediated by habitat type for these species, because their response to the treatments was different in IAG versus NAG. We speculate that the response to competitors is actually determined by the relative quality of each habitat type for each species. We explore this further with the two focal species of Grasshopper Sparrow and Bobolink.

For Grasshopper Sparrow, the loss vs. stability odds ratio was larger in NAG than in IAG (Electronic Appendix 3 ), which means that the odds of no change were substantially greater in NAG than IAG. Further, the magnitude of the loss vs. stability odds ratios for IAG and NAG indicates the probability of losing Grasshopper Sparrow was greater than the probability of no change in IAG, while in NAG the probability of no change was greater than the probability of loss. This suggests that the placement of GRSP treatments resulted in deterrence of Grasshopper Sparrow from IAG, but had no effect in NAG. Further, the odds of gaining Grasshopper Sparrow are substantially greater in NAG than in IAG (Electronic Appendix 3). In IAG, the probability of loss is greater than the probability of gain, while in NAG, the probability of gain is greater than the probability of loss. Grasshopper Sparrows are attracted by the (simulated) presence of GRSP but only in the high-quality NAG sites; they are deterred by the same at the comparatively lower-quality IAG sites. This is an important result, as it has previously been demonstrated that conspecific social cues can influence habitat selection but it was unknown whether these cues could trump habitat quality (Ward and Schlossberg 2004, Ahlering and Faaborg 2006, Ahlering et al. 2006, Fletcher 2006). It is of conservation interest to determine the relative importance of vegetation versus social cues, as it is important that we avoid inadvertently attracting birds into habitat of poor quality (Ahlering et al. 2010). Our results demonstrate that for Grasshopper Sparrows, social information does not override habitat quality cues; the birds react differently to the presence of conspecifics based on the habitat type. This is in contrast to Nocera et al. $(2006,2009)$ who found that for Bobolinks, conspecific attraction overrode habitat quality for young birds and new emigrants. However, all fields used in their study were NAG and therefore of higher quality for Bobolinks than any IAG field, making it difficult to predict the strength of conspecific attraction for Bobolinks in poor quality habitats (Nocera et al. 2009). Our findings also contrast what Betts et al. (2008) found with forest birds, suggesting that the relative importance of vegetation and social cues may differ between species or guilds based on habitat quality.

The odds of gain for Bobolink when exposed to GRSP treatments are substantially greater in NAG than in IAG 
(Electronic Appendix 3). In IAG, the probability of losing Bobolink is greater than the probability of gain, while in NAG the probability of gaining Bobolink is greater than the probability of loss. These results suggest that they are deterred from IAG sites treated with GRSP, but are attracted to NAG sites treated with GRSP, which indicates heterospecific attraction in sites of good quality.

The attraction of Bobolinks to Grasshopper Sparrows makes sense, as heterospecific information is more valuable if it comes from another species which fills a similar ecological niche (Parejo et al. 2004, Seppänen et al. 2007), and Bobolinks and Grasshopper Sparrows have similar habitat use patterns, particularly within the agro-ecosystems of southern Ontario (Martin and Gavin 1995, Vickery 1996 , McGuire 2014). The cost of using heterospecific information is also less for competitively dominant species (Forsman et al. 2002, Fletcher 2007), which, when coupled with our $\mathrm{C}$-score results, suggests that Bobolinks are dominant over Grasshopper Sparrows. That Bobolinks were attracted to the presence of Grasshopper Sparrows only in habitats of good quality suggests they use social cues as a basis for evaluating habitat but update this with real-time information on accuracy. Further study might focus on the effects of population density on heterospecific attraction in grassland birds, as it has been demonstrated that density can change the costs and benefits of social information for forest birds (Fletcher 2007).

Bobolink and Grasshopper Sparrow use IAG the least of the three habitat types (McGuire 2014), suggesting that IAG is lower quality habitat for these two species. We have now shown that the loss of both species in IAG habitat is more likely under simulated GRSP presence. This suggests that competition between these two species is mediated by habitat type; when the habitat is of poor quality, Bobolink and Grasshopper Sparrow avoid competing for resources. This avoidance of interspecific competitors has been previously documented by Betts et al. (2010) and Fletcher (2007), but they did not examine this response across multiple habitat types. Conversely, our data show that both Bobolink and Grasshopper Sparrow are more likely to settle in NAG sites where the presence of GRSP has been imitated. When taken with the previous result, this is further evidence for habitatmediated competition, as these species appear willing to compete when habitat is of good quality.

As agricultural intensification increases in southern Ontario, the amount of IAG habitat will increase at the cost of reducing the amount of NAG and NCM. To persist, grassland bird species which previously avoided or did not use IAG may have to adjust to breeding in that habitat type, at both an individual and population level. This could lead to increased competition levels on these sites, as species which use IAG habitat (e.g., Vesper Sparrow) experience an influx of species which were not present before (e.g., Eastern Meadowlark). Species such as Grasshopper Sparrow and Bobolink, which currently avoid competing in IAG fields, may be forced to coexist. The outcomes of such new and forced interactions are unknown and should be considered when implementing management plans in agro-ecosystems. Dominant species might successfully adjust to breeding in IAG and therefore mitigate any population loss, but species that lose competitively may suffer accelerated population declines. It should be noted that our study evaluated competition based on exclusion, but it is possible for competitors to coexist within the same site, and interesting further research could focus on relative species abundance as opposed to presence-absence. Such understanding of how habitat type affects both conspecific and interspecific interactions is crucial to the successful conservation of grassland bird communities.

Acknowledgements: We would like to acknowledge the funding support of the Ontario Ministry of Natural Resources and Forestry, the Natural Sciences and Engineering Research Council of Canada, Trent University, and the Nature Conservancy of Canada. We would also like to thank E. Kellogg for her valuable assistance in the field. Comments from J. Schaefer, E. Nol, and an anonymous reviewer greatly improved the draft manuscript.

\section{References}

Ahlering, M.A. and J. Faaborg. 2006. Avian habitat management meets conspecific attraction: If you build it, will they come? Auk 123: 301-312.

Ahlering, M.A., D.H. Johnson and J. Faaborg. 2006. Conspecific attraction in a grassland bird, the Baird's Sparrow. J. Field Ornithol. 77: 365-371

Ahlering, M.A., D. Arlt, M.G. Betts, R.J. Fletcher Jr., J.J. Nocera and M.P. Ward. 2010. Research needs and recommendations for the use of conspecific attraction - Methods in the conservation of migratory songbirds. Condor 112: 252-264.

Askins, R.A. 1993. Population trends in grassland, shrubland, and forest birds in eastern North America. Curr. Ornithol. 11: 1-34

Askins, R.A. 2000. Restoring North America's Birds: Lessons from landscape ecology. Yale University Press. New Haven, CT, USA.

Betts, M.G., A.S. Hadley, N. Rodenhouse and J.J. Nocera. 2008. Social information trumps vegetation structure in breeding-site selection by a migrant songbird. Proc. Roy. Soc. Lond. B Biol. 275: 2257-2263.

Betts, M.G., J.J. Nocera and A.S. Hadley. 2010. Settlement in novel habitats induced by social information may disrupt community structure. Condor 112: 265-273.

Boren, J.C., D.M. Engle and R.E. Masters. 1997. Vegetation cover type and avian species changes on landscapes within a wildlandurban interface. Ecol. Model.103: 251-266

Bruno, J.F., J.J. Stachowicz and M.D. Bertness. 2003. Inclusion of facilitation into ecological theory. Trends Ecol. Evol. 18: 119-125.

Carey, M., D.E. Burhans and D.A. Nelson. 2008. Field Sparrow (Spizella pusilla). In: A. Poole (ed.), Birds N Am Online. Cornell Lab of Ornithology, Ithaca, New York.

Cavitt, J.F. and C.A. Haas. 2000. Brown Thrasher (Toxostoma rufum). In: A. Poole (ed.), Birds N Am Online. Cornell Lab of Ornithology, Ithaca, New York.

Connor, E.F. and D. Simberloff. 1979. The assembly of species communities: chance or competition? Ecology 60: 1132-1140.

Conover, R.R., S.J. Dinsmore and J.W. Burger. 2011. Effects of conservation practices on bird nest density and survival in intensive agriculture. Agr. Ecosyst. Environ. 141: 126-132. 
COSSARO. 2010. COSSARO Candidate Species at Risk Evaluation Form for Bobolink (Dolichonyx oryzivorus). 1-7.

COSSARO. 2011. COSSARO Candidate Species at Risk Evaluation Form for Eastern Meadowlark (Sturnella magna). 1-15.

Elton, C. 1946. Competition and the structure of ecological communities. J. Anim. Ecol. 15: 54- 68.

Entsminger, G.L. 2012. EcoSim Professional: Null modeling software for ecologists, Version 1. Acquired Intelligence Inc., Kesey-Bear, \& Pinyon Publishing. Montrose, CO. http://www. garyentsminger.com/ecosim/index.htm

Fletcher, R.J. Jr. 2006. Emergent properties of conspecific attraction in fragmented landscapes. Am. Nat. 168: 207-219.

Fletcher, R.J. Jr. 2007. Species interactions and population density mediate the use of social cues for habitat selection. J. Anim. Ecol. 76: 598-606.

Forsman, J.T., J.T. Seppänen and M. Mönkkönen. 2002. Positive fitness consequences of interspecific interaction with a potential competitor. Proc. Roy. Soc. Lond. B Biol. 269: 1619- 1623.

Gotelli, N.J. 2000. Null model analysis of species co-occurrence patterns. Ecology 81: 2606- 2621.

Hardin, G. 1960. The competitive exclusion principle. Science 131: 1292-1297.

Heckenlively, D.B. 1976. Cadence of Field Sparrow songs. Wilson Bull. 88: 588-602.

Jaster, L.A., W.E. Jensen and W.E. Lanyon. 2012. Eastern Meadowlark (Sturnella magna). In: A. Poole (ed.), Birds N Am Online. Cornell Lab of Ornithology, Ithaca, New York.

Johnson, L.S. 1998. House Wren (Troglodytes aedon). In: A. Poole (ed.), Birds N Am Online. Cornell Lab of Ornithology, Ithaca, New York.

Jones, S.L. and J.E. Cornely. 2002. Vesper Sparrow (Pooecetes gramineus). In: A. Poole (ed.), Birds N Am Online. Cornell Lab of Ornithology, Ithaca, New York.

Martin, S.G. and T.A. Gavin. 1995. Bobolink (Dolichonyx oryzivorus). In: A. Poole (ed.), Birds N Am Online. Cornell Lab of Ornithology, Ithaca, New York.

McGuire, S.L. 2014. Habitat use and community structure of grassland birds in southern Ontario agro-ecosystems. Master's Thesis, Trent University, Peterborough, ON. viii +120 pp.

Miller, G.T. Jr. and D. Hackett. 2011. Living in the Environment (2nd Canadian ed.). Nelson Education Ltd., Toronto, Ontario.

Mönkkönen, M., P. Helle and K. Soppela. 1990. Numerical and behavioral responses of migrant passerines to experimental manipulation of resident tits (Parus spp.): Heterospecific attraction in northern breeding bird communities. Oecologia 85: 218-225.

Nocera, J.J. and M.G. Betts. 2010. The role of social information in avian habitat selection. Condor 112: 222-224.

Nocera, J.J., G.J. Forbes and L.-A. Giraldeau. 2006. Inadvertent social information in breeding site selection of natal dispersing birds. Proc. Roy. Soc. Lond. B Biol. 273: 349-355.

Nocera, J.J., G.J. Forbes and L.-A. Giraldeau. 2009. Aggregations from using inadvertent social information: a form of ideal habitat selection. Ecography 32: 143-152.
Parejo, D., E. Danchin and J.M. Aviles. 2004. The heterospecific habitat copying hypothesis: can competitors indicate habitat quality? Behav. Ecol. 16: 96-105.

Pinheiro, J., D. Bates, S. DebRoy, D. Sarkar and the R Development Core Team. 2013. nlme: Linear and Nonlinear Mixed Effects Models. R package version 3.1-109.

Proppe, D.S. and G. Ritchison. 2008. Use and possible functions of the primary and sustained songs of male Grasshopper Sparrows. Am. Midl. Nat. 160: 1-6.

R Development Core Team. 2013. R: A language and environment for statistical computing. R Foundation for Statistical Computing, Vienna, Austria. URL http://www.R-project.org/

Ray C., M. Gilpin and A.T. Smith. 1991. The effect of conspecific attraction on metapopulation dynamics. Biol. J. Linn. Soc. 42: 123-134.

Roughgarden, J. 1983. Competition and theory in community ecology. Am. Nat. 122: 583-601.

Seppänen, J.-T., J.T. Forsman, M. Mönkkönen and R.L. Thomson. 2007. Social information use is a process across time, space, and ecology, reaching heterospecifics. Ecology 88: 1622-1633.

Sinclair, A.R.E. 1991. Science and the practice of wildlife management. J. Wildlife Manage. 55: 767-773.

Starkweather, J. and A.K. Moske. 2011. "Multinomial Logistic Regression." Retrieved from: http://www.unt.edu/rss/class/Jon/ Benchmarks/MLR JDS Aug2011.pdf

Strong, D. Jr., L. Szyska and D. Simberloff. 1979. Tests of community-wide character displacement against null hypotheses. Evolution 33: 897-913.

Styring, A.R., R. Ragai, J. Unggang, R. Stuebing, P. Hosner and F.H. Sheldon. 2011. Bird community assembly in Bornean industrial tree plantations: Effect of forest age and structure. Forest Ecol. Manage. 261: 531-544.

Terborgh, J. 1985. Habitat selection in Amazonian birds. In: M.L. Cody (ed.), Habitat Selection in Birds. Academic Press, New York, NY. pp. 311-338.

Venables, W.N. and B.D. Ripley. 2002. Modern Applied Statistics with $S$ (4th Edition). Springer, New York.

Vickery, P.D. 1996. Grasshopper Sparrow (Ammodramus savannarum). In: A. Poole (ed.), Birds N Am Online. Cornell Lab of Ornithology, Ithaca, New York.

Ward, M.P. and S. Schlossberg. 2004. Conspecific attraction and the conservation of territorial songbirds. Conserv. Biol. 18: 519-525.

Received October 23, 2014

Revised February 14, April 20, 2015 Accepted May 6, 2015

\section{Electronic Appendices 1-3}

Checkerboard scores for species-of-interest pairs, betweenyear occupancy changes, and the magnitude of the difference in odds ratios, all referenced in the paper. The file may be downloaded from the web site of the publisher at www.akademiai.com 